Article

\title{
What Do You Expect? Linguistic Reflections on Empathy in Science Communication
}

\author{
Nina Janich \\ Institute of Linguistics and Literary Studies, Technische Universität Darmstadt, 64293 Darmstadt, Germany; \\ E-Mail: nina.janich@tu-darmstadt.de
}

Submitted: 23 September 2019 | Accepted: 23 January 2020 | Published: 18 March 2020

\begin{abstract}
This linguistics article, which draws additionally on interdisciplinary insights, discusses whether and to what extent more empathy could facilitate and promote the exchange of knowledge between science and society. The existence of the Internet as a knowledge resource has made it necessary, especially in online communication, to renegotiate (scientific) expertise and roles such as 'expert' and 'layperson.' A discourse linguistics case study of a science blog shows that these negotiations quickly take on the character of an emotionally charged relationship between writer and respondent and are by no means limited to the level of fact or disinterested scholarly debate. The reason for this-so this article argues-is that reciprocal expectations and expectations of expectations play an essential role in science communication, as in any social communication. This hypothesis is supported by an analysis of interviews with scientists about their expectations of the public's understanding of science. Against this background, empathy seems to be a suitable means to better meet the expectations of one's interlocuter (or at least to avoid disappointed expectations) and to move from a more emotional level back to a more rational one. Empathy and its role in science communication should therefore be investigated more closely-on an interdisciplinary basis.
\end{abstract}

\section{Keywords}

discourse linguistics; emotionality; empathy; expectations of expectations; science communication

\section{Issue}

This article is part of the issue "Emotions and Emotional Appeals in Science Communication" edited by Monika Taddicken (Technische Universität Braunschweig, Germany) and Anne Reif (Technische Universität Braunschweig, Germany).

(C) 2020 by the author; licensee Cogitatio (Lisbon, Portugal). This article is licensed under a Creative Commons Attribution 4.0 International License (CC BY).

\section{Introduction}

In 1996, Jäger identified a crisis of expert culture, which he traced back primarily to an increasing compartmentalization and specialization in science and technology, but also to a lack of transparency in expert knowledge. In 2012, Beckers postulated a stronger cooperative construction of knowledge, calling for the participation of both 'patient experts' and 'knowledgeable laypersons' alike. Both postulates are based on the classic deficit model of expertise which "is traditionally thought of as a social practice consisting of an asymmetrical, hierarchical relationship between at least two participants: the knowledgeable expert and the less knowledgeable advisee" (Eriksson \& Thornborrow, 2016, p. 1; see also Weingart, 2003). The large number of online resources and social media platforms (especially blogs, Twitter, etc.) has since become an important resource, freely available, of different kinds of knowledge and expertise, one that also influences the relationship between science and the public and between experts and laypersons in general (e.g., Brossard \& Scheufele, 2013; Dudo, 2013; Weingart \& Guenther, 2016). The classical understanding of expertise should accordingly be subjected to critical reflection and be understood as a "highly complex phenomenon" (Eriksson \& Thornborrow, 2016, p. 1). Those who claim expertise must also renegotiate their identity as an expert in a-possibly unexpected-linguisticdiscursive way, because scientific writing in fora other than the traditional scientific ones is not endowed with the same authority found there (Hyland, 2009): 
A scientist speaking at a public forum, for example, might shift in and out of speaking as an expert. Expertise discourse then becomes a communicative ability as a marker of expert behaviour, which could be locally marked by level of knowledge, professional experience, firsthand experience, or professional judgment. (Sprain \& Reinig, 2017, p. 3)

In this context, then, it is also a matter of the construction and acceptance of social identities:

Presenting oneself as a particular kind of person therefore involves making rhetorical choices which meet a particular community's assumptions, bodies of knowledge, and ways of seeing. So, we embed our writing in a particular social world which we reflect and conjure up through approved discourses....This means that identity involves both shared norms and personal traits....For academics, it is how we achieve credibility as insiders and reputations as individuals. (Hyland, 2009, pp. 26-27; see also Motta-Roth \& Scotti Scherer, 2016)

If we examine science blogs and the comments written by the blogs' readers, for example, we quickly notice that the discussion here is characterized by different types of expertise (Sprain \& Reinig, 2017) and has long left the level of facts and content (Kuteeva, 2016). The participants' roles-by no means free of conflicting affiliations in other ways as well (Maillé, Saint-Charles, \& Lucotte, 2010)-are therefore much less clear, with communication quickly changing from the objective to the personal level: Expert and lay roles are then renegotiated, and the right to speak as well as communication styles become a subject of heated dispute.

Against this background, the present article argues for and discusses from a linguistic point of view the hypothesis, first, that greater empathy among all participants could facilitate the negotiation of social identities in (online) science communication and could thus bring about a quicker and smoother return to the issue-or to participants not leaving the scientific, objective level in the first place. This is because-to introduce the second hypothesis-more empathy could lead to fewer expectations being disappointed: be it because they are already empathically anticipated or because, in the event of conflict, an effort to empathize renders them clearer. The article suggests that an examination of empathy in scholarly communication would be a worthwhile field of interdisciplinary research (Schneider, 2019); it would be fruitful to focus on the specific expectations of empathy, the different possible forms in which empathy can be generated, and the signs of a willingness to empathize on the part of the various actors (Bender \& Janich, 2020).

The theoretical background of the article is briefly outlined below. First and foremost, the sociological concept of 'expectation' (and its reciprocal extension, the 'expectation of expectation') is examined in relation to the philosophical and psychological concept of 'empathy' and to a linguistics approach to 'emotion' (Section 2). We then explain how the research proceeded and how the database was assembled (Section 3): Interviews with scientists who possess many years of experience in communicating science to broader publics are used as an initial empirical source to determine which public expectations scientists usually assume, i.e., around which expectations they usually focus their communication, for example when blogging (Section 4). Finally, some examples of comments left on a science blog are analysed linguistically to show in concrete terms which expectations actually play a role among readers and commentators, how their possible disappointment affects communication, and to what extent empathy may contribute to resolving the ensuing communicative conflicts (Section 5).

\section{The Theoretical Background: Expectations, Empathy, and Emotion}

\subsection{Expectations and Expectations of Expectations}

Interaction is the condition on which the possibility of society depends. If groups of people are to manage to live together, there is a certain need for communication and thus for cooperative action more generally. This common action is coordinated and made possible by what are termed expectations. Drawing on Luhman (1976), Klenk outlines the relevant aspects of this concept:

a) expectations, in this context, must not be understood as expectations of human minds; the expectations are realized as forms of communication in the medium of meaning...; b) expectations, as communication itself, become observable only in retrospect; expectations are bound to their response, particularly their disappointment. Only by the reply it becomes observable what has been expected....And, c) the selection and stabilization of expectations as structures of social systems can only be constituted on the level of expectations of expectations (German: Erwartungserwartungen, cf. Luhmann, 1976, 63f), which means that expectations only gain structural relevance for social systems, if they are themselves expected, which in turn means that they must be observed. (Klenk, 2013, p. 177)

According to this theory, in our actions we learn to expect the expectations of the other individual and to act accordingly. Further, we assume that the other person is competent and willing to expect our expectations and to act accordingly him- or herself. This postulate of reciprocal expectations of expectations explains how social and rhetorical norms develop from it. It also directs our attention to the consequences of disappointed expectations for communication (here: communicating science) and the potential that empathy may offer for resolving communicative conflicts. 


\subsection{Empathy}

Empathy is conceived as the fundamental prerequisite for all understanding, and thus also for the possibility of anticipating expectations (Hermanns, 2007b). Philosophical approaches see empathy more precisely as a phenomenon that can be understood multidimensionally and in the sense of a stage model. In this multidimensionality, the concept of empathy becomes closely related to the concept of the reciprocal and observable expectation: Empathy is viewed on the one hand as existing in the inner world of the subject (as a situation-specific sympathetic understanding), and on the other hand as a form of negotiation and recognition within a community with shared norms (and thus also across situations; Breyer, 2013). Additionally, empathy can also mean 'taking sides in a scene of three,' in other words, when a third party mentally takes sides with one of the other two parties involved (Breithaupt, 2009). For science communication, this third aspect is an important extension of the originally dyadic model of empathy. Empathy as a stage model means that different degrees of empathy can be assumed: from basic forms such as perceiving another's emotions and being moved by them to putting oneself in the place of the other person and imagining how one would act if one were that person (Breyer, 2013). To summarize dimensions and stages, the following types of empathy can be identified (Breyer, 2013; Hoffman, 2000; for more detailed discussion see Bender \& Janich, 2020) - set here in relation to the concepts of expectation vs. expectation of expectations:

1) Global empathy: Meaning only a general acceptance of the condition of the other in a vague and general way, without anticipation of possible specific expectations (i.e., formation of expectation only, not of differentiated expectations of expectations);

2) Egocentric empathy: Such empathy is based on a clear awareness of difference (me/the other person), one's assessment of the other person is based on one's own standards, an expectation of expectations is based only on one's own horizon of expectations as shaped by the situation;

3) Allocentric empathy: This concerns a genuine attempt to empathize with the other person (in light of his/her background, according to his/her standards) and thus entails, among other things, an attempt to actually anticipate, as far as possible, the expectations of the other person from his/her perspective and to take them seriously as expectations of expectations in one's own communicative actions;

4) Symbolically mediated empathy: This does not take place in one's own immediate experience, but arises on the basis of reports and judgements, i.e., for example on the basis of explicit and formulated expectations, reports of disappointed expectations, etc., in the sense of positive recognition of these expectations;

5) Empathy with groups: This special form, which extends to more than one counterpart, is based on a medialization and collectivization of the aforementioned symbolically mediated empathy.

In addition to this distinction concerning with whom one feels empathy and why, we must identify three dimensions which are analytically relevant for our evaluation of the blog and interview material, because a clearer distinction can be made here between the normative and the descriptive level: on the descriptive level it can be shown who actually shows empathy towards whom and with what linguistic means they do so (dimension of empathy generation). For the hypotheses to be tested here, however, the normative level seems particularly important, i.e., the question of where empathy is explicitly formulated as an expectation of the counterpart and where the attempt is actually made to meet this expectation by making concessions and offering options (dimensions of empathy expectation or empathy readiness).

\subsection{Emotion}

The concept of empathy is linked to the concept of emotion in classical dyadic models of empathy by placing it between mind and sensuality. Breyer points out, however, that such dualistic tendencies neglect the complex interactions of empathy with emotional, affective, and rational factors against the background of observations, memory, and knowledge (Breyer, 2013). Linguistically, it is of particular interest how emotion affects the negotiation of roles and the discussion of expectations and disappointments, i.e., when (and how and why), for example, a change from the factual level to the relationship level takes place. Emotionality is reflected linguistically either in the use of explicitly descriptive expressions for emotions (such as "annoy," "disturb," "rejoice") or in expressive speech acts (such as praise, scolding, consolation, but also, for example, in the use of irony or the offer of personal insights). One of the hypotheses of this article concerns the rationality of empathy to cope with this emotional level within science communication without losing credibility and trustworthiness (Schneider, 2019).

\section{Data and Methods}

The following is a two-step procedure: First, using interview material (1), I examine the expectations that scientists have about the public's expectations when they are dealing with the possibilities and limitations of external science communication (in other words, the expectations of expectations beyond their own expectations and attitudes towards science communication, as explored by, e.g., Herrmann-Giovanelli, 2013). In this way, I reconstruct the fundamental orientations that guide scientists' 
communication (Section 4). Against the background of these reconstructions, I examine a case of external science communication in the form of a science blog and the discussion triggered by it (2) to see how this interplay of expectations and language action works in direct contact with the public-and what conflicts arise (Section 5).

\subsection{Step 1 (Data)}

In Section 4 below, interview statements are evaluated in order to identify the expectations of expectations on the part of scientists that might serve as a practical orientation for them in external science communication. The interviews with scientists that form the basis of this study were conducted in 2018 and 2019 as part of a project (2018-2022) funded by the Klaus Tschira Foundation entitled "Textual Competence of Young Researchers in Science." The aim of the evaluation within the framework of the project is to reconstruct critical communication situations in order to develop hypotheses regarding the nature of science communication among young scholars in the natural sciences. The database consists of transcripts from 17 structured narrative interviews, each of which lasted about 40-90 minutes. Since the interviews were conducted in German, the spoken text was transcribed and then carefully edited for an intelligible translation into English. The interview questions concerned good and bad experiences in communication between scientists and the public and, in particular, the question of whether and how scientific uncertainties should be addressed in science communication. All the scientists who were interviewed have several years of experience in communicating science to journalists and the wider public.

\subsection{Step 1 (Methods)}

For the present article, the interviews were evaluated selectively with regard to whether the expectations of certain actors are explicitly mentioned and reflected on by the scientists and, if so, which ones. To this end, all the interviews were searched for word tokens of "expect-" (German original: "erwart-"), and the corresponding passages and their co-text were evaluated with regard to forms of argumentation. The corresponding code units are derived from the syntactic valency of the verb to expect ('who expects what of whom when/in which context'): whose expectations-expectations with regard to what and how/when-and, to take account of the reciprocal character of expectations and the dyadic character of communication, the speaker's/writer's own attitude toward those expectations. Passages in which the scientists expressed expectations concerning future research results were not taken into account. Since the aim is to make only an initial inventory of the connection between expectations of expectations and their influence on science communication, passages on expectations of expectations only expressed implicitly were ignored in this first evaluation.

\subsection{Step 2 (Data)}

On the portal Scilogs-Tagebücher der Wissenschaft (offered by the German publishing house Spektrum der Wissenschaft), science journalists maintain a blog along with several prominent German scientists. In the column Climate Lounge, a blog about an expert hearing in the Environment Committee of the Lower Saxony regional parliament on global warming in June 2014 contains a statement by a climate scientist concerning an expert opinion heard by the committee in question. In Section 5 , the comments posted on this science blog will be used to examine linguistically which expectations are prompted and which ones influence communication when scientists and the public communicate directly with one another, without professional mediators (see blog and comments in Rahmstorf, 2014). The blog was chosen for analysis because: (1) it refers to a topic that has been the subject of heated debate in recent years (greenhouse effect/global warming); and (2) because it deals specifically with the people involved in the controversy in the science-policy nexus. These two factors serve to generate a debate on the role of scientists and of policy makers that is both intense and explicit, which is why the example is particularly well suited to show in a nutshell which expectations can collide in science communication and to explore the role that (more) empathy can or might play in resolving conflicts. The results are suited merely to highlighting some phenomena which should be examined more closely and with regard to the different kinds of science blogs (including different audiences and commentators) and social media formats (e.g., Kuteeva, 2016; Schäfer, 2017; Sprain \& Reinig, 2017). The aim of the case study is thus to identify issues of interest search instructions for later, more detailed investigation.

\subsection{Step 2 (Methods)}

The German excerpts from the comments section of this blog concerning the criticism of one of the experts heard by the committee were translated into English and were used to illustrate how quickly the communication and negotiation of assigned or claimed roles (e.g., expert vs. layperson) and associated role expectations (e.g., concerning both the comprehensibility of the expert's explanations and his expertise in the subject matter) (can) become emotionally charged. The approach chosen here is a discourse hermeneutic interpretation (Hermanns, 2007a) of linguistic keywords and discourse patterns which indicate emotions (expressive speech acts or affective formulations; see Section 2.3), role assessments (explicit role descriptions/names or legitimizing references to training, knowledge, etc.; see Section 1) and the implicit or explicit mention of expectations-for more empathy, for example (see Sections 2.1 and 2.2).

Since I am dealing with a normative question, namely, whether empathy is a relevant dimension in science communication and should thus receive greater at- 
tention in the future, this study takes an exploratory and hermeneutic approach. The aim is to achieve the highest possible plausibility with regard to the above hypotheses by linking an analysis of scientists' reflections on the meta-level about the expectations they encounter or assume (interviews) with an analysis of actual communication (blog comments).

\section{Scientists' Expectations of Expectations with Regard to the General Public}

Based on their experiences when communicating science to a wider public, the scientists interviewed are aware that people outside science have certain perceptions and expectations of science. The scientists address these expectations in a very concrete and differentiated way, often immediately reflecting upon them in a normative, differentiated, and empathic manner. Therefore, the following section will first present the expectations of expectations of the scientists interviewed reconstructed from interview excerpts (passages in the co-text of word tokens of "expect-"/German: "erwart-"; Subsections 4.1-4.4), followed by the scientists' reflections on the exchange. A few quotations from the interviews are provided (samples 1-10) to show how close reading and hermeneutic interpretation led to the reconstructions offered. A few brief comments shall indicate some of the conclusions that can be drawn from the analysis.

Below I identify the expectations of expectations on the part of the scientists from the interviews I analysed.

\subsection{Expectation of the Expectation that 'Science is Complex'}

Scientists' reflections in a nutshell: 'Science should communicate not only results, but also methods and cognitive processes to enable a better understanding of science and its findings.'

Sample quotation 1: But people should see, wow, that's really complex, that's always bound up with it. That's what people expect from science somehow, but certain things that might be important for the interpretation you try to explain....I've noticed that people are really into that....And this is not to demand that people understand that, but that they are at least taken along with you a little, taken briefly into science or into the laboratory.

Sample quotation 2: The second point is that I think it is important that everyone understands how science works. Somehow, you have to understand it. It's not just the result that's important, it's the story, how do I arrive at a result?

Sample quotation 3: People ask a lot more about the animals or the results themselves, that's quite obvi- ous, that's what it's about, but people do also ask about methodological backgrounds....It's noticeable that people are pleased to be involved in this scientific process a little bit.

The quotations show that scientists see the benefit of the mediation of scientific knowledge and work processes, for three reasons: (1) because they can remain more authentic themselves; (2) because their audience feels that they are being taken more seriously; and (3) because they hope that the results, which are usually the main reason for and the subject of communication, can be better understood and evaluated. This leads us directly to the expectation regarding the certainty/uncertainty of scientific findings.

\subsection{Expectation of the Expectation that 'Scientific Knowledge Is Certain Knowledge'}

Scientists' reflections in a nutshell: 'Omnipresent uncertainties should be communicated honestly and as transparently as possible in order to counter this false expectation/change this expectation in the long term.'

Sample quotation 4: I believe that it is important for a scientist to talk about the uncertainties, because of course otherwise he is committing himself to a certain version. However, I think this is fairly difficult to communicate to the public, because...they always expect scientists to be able to state clearly what the situation is, indeed, what the definite facts are. Scientists certainly can say what the situation is, but you just have to see the whole picture, how this knowledge was arrived at. And that, I think, is a bit difficult for the public to judge.

Sample quotation 5: Well, if I were to claim that there are no uncertainties, that would be a lie. And in the sense that we say we try to generate true insights with science, and we try to reach an agreement on this, you have to somehow communicate the uncertainty too. You would also create false expectations if you said that something is one hundred percent certain if it's not one hundred percent certain. So I think that's the normal way of dealing with scientific findings, that you know you can call them uncertain and then you deal with them.

The two quotations show how important it is for scientists to counter the often false public expectation of scientific certainty (especially in the case of complex topics) through honesty and transparency when dealing with their findings - not least in order to achieve a better understanding of science itself. There are, however, rather varying attitudes concerning the extent to which scientists actually react appropriately to this issue or whether the way they do so does not rather contribute toward affirming these expectations: 
Sample quotation 6: In my opinion, the [scientific uncertainties] are barely presented. Because it would simply take far too long in these fast-moving times to clarify these uncertainties, and nobody wants to listen anymore....And maybe that's the reason why people don't want to take science so seriously anymore, because they like to expect definitive statements....But there are many things science cannot speak about definitively. I think there's a complete lack of awareness in the public sphere....Somehow one expects that these are data, firm data, and that is the wrong expectation. And of course, the natural sciences work out data, not opinions, but the data, they are just interpreted, and then I have opinions.

\subsection{Expectation of the Expectation that 'Science Should Provide Diagnosis and Problem Solving, Responsible} Expertise Knowledge and Recommendations for Action'

Scientists' reflections in a nutshell: 'Science communication should not only impart knowledge, but also present this as a central task of science.'

Here too the scientists interviewed discuss the public's expectations, of which they are critical and which they wish to correct. From their perspective, empathy can only involve responding to this expectation while at the same time showing that it is everyone's responsibility, and not just the task of scientists, to draw the corresponding conclusions from scientific findings. In other words, it is everyone's responsibility to decide which conclusions are to be drawn for oneself and for collective action:

Sample quotation 7: There will be more frequent enquiries [concerning the research topic], but then the question immediately following that will usually be 'what should I do now if it's so uncertain?' And then there's the debate, people again expect that scientists or science should say what every one of us should do now, that would be the most convenient thing. And then we have the role science can play in democracy, and well, then you can say what you yourself would do now or what you consider ethically justifiable....Well, then I try to communicate that everything, our whole life, is just constantly uncertain and we constantly make decisions nevertheless and have actually got quite used to it and don't always want to ask or shouldn't always ask experts either. I think I always try to put the responsibility back on every one of us.

In this context, communication problems are discussed in relation to the extent to which science communication is useful or suited to changing attitudes and ways of behaving-e.g., in view of selective perception and the use of information:

Sample quotation 8: People's expectations of what they want to hear are much stronger than they used to be....And the masses go in with certain expecta- tions of what they actually want to hear. That is, there are people who want to hear about catastrophes, that humans are so bad, and they just want to hear that humans have ruined everything. And then there is another group, they just want to hear that everything is not so bad...but they just come along with a certain hope, 'I hope he says what I actually want to hear.' But you can have good discussions with them. They are happy to argue with you and you can put them on a scientific track. These ideological people, it's not worth it, with them you can break off the discussion after two minutes.

The public expectation that science also makes key decisions for society and politics is ultimately rejected by all the scientists we interviewed, usually by referring to their different roles in society (e.g., 'as a scientist' vs. 'as a citizen')-and clearly this stance has not caused them any difficulty:

Sample quotation 9: And then I am also completely honest at this point, because I also think I don't want to be the better fellow citizen here. I am just-in a way I have access to knowledge that others don't have, and I like to try to make it available, without dogmatically coming along and saying what you have to do. And that, I have noticed, is very well received.

\subsection{Expectation of the Expectation that '(Every) Science Communicates its Findings'}

Scientists' reflections in a nutshell: 'Science should carry information outwards in various ways, but also make clear where there is a specialization/division of labour and that this poses limitations.'

Sample quotation 10: But of course this allows us to take the liberty of maintaining a broad research portfolio and keeping experts on hand: some do one thing, others do another, others do another thing altogether. But in communication, it's expected of the other person, and also of society, that you talk about things in depth, which is always very exciting, because it's kind of great and fascinating-you can generate a sense of the fascination of research with really weird, specialist topics that everyone just thinks are great. But if you have a question where you want to have orientational knowledge, like how you should behave...then what you want is more reflective, more balanced, more broadly supported knowledge, and in the German science system this is not so easy to get. You'll find a lot of experts on something, but they'll all be stuck for answers pretty quickly, because it's a very differentiated system.

While none of the interviewees denied that scientists have a basic duty to communicate scientific knowledge, some of them immediately respond by discussing the different opportunities, media, and channels for doing so 
and the differing extent to which these are able to fulfill said expectations (including the broad understanding that even a conversation with a neighbour about one's own work is also a-by no means negligible-form of science communication). With the scientists' reflections on the expectation that the public desires orientational knowledge, we once again come full circle to expectations of expectations and scientists' own aspiration that, despite the complexity of its problems, it should contribute as much as possible to the public's understanding of its findings.

All in all, the interviews show that the scientists interviewed explicitly formulate expectations with regard to the public. However, they do not anticipate or address the expectations that science journalists and communicators may have of scientists in the same way. These actors are obviously considered not so much addressees as cooperation partners in communicating science to the wider public. This can be seen from the fact that the interviewees focus more on the expectations they have of these partners (e.g., good research, a minimum of prior knowledge, correct representation, support in formulating findings in an understandable way).

\section{Expectations, Emotionality, and Empathy in the Science Blog}

\subsection{The Core Conflict: Disputed Expertise and Disappointed Expectations}

The quotations presented below are taken from the science blog's comments section, a prototypical example of science blog communication (Kuteeva, 2016) containing well over 100 comments in this case (Rahmstorf, 2014). The quotations show the core conflict that runs parallel to the factual and technical discussion about (inter alia physical) causes, processes, and degrees of global warming, namely, that one of the experts invited to give evidence is a controversial figure, both with regard to his claimed expertise and to the statements he made to the Environment Committee. The scientist who writes the blog discusses in his post both the position taken by this invited expert and the scientific context, his aim being to provide correction and clarification.

The italics in the following quotations denote assigned or claimed roles while underscoring denotes a judgement about a role (and thus implicitly fulfilled or unfulfilled role expectations). The original blog and comments are in German and are translated here into English. Bracketed omissions refer to omissions within a comment, not to unquoted comments. The following explanation points out the linguistic keywords, discourse patterns, and arguments which underlie the hermeneutic interpretations of this case study example.

Example Sequence 1:

1) Commentator nickname A (23 June 2014 11:31): How can it be that "experts" like Mr. [criticized expert] are invited to an "expert hearing by the Environment Committee"? Of course I understand that as a politician you can't know about everything, but you should be able to distinguish between a competent advisor and a charlatan with completely obvious pied piper arguments! If this is what realpolitik looks like, then good night.

2) Expert criticized in the blog (23 June 2014 15:25): Another one calling for censorship! And he throws insults but doesn't mention his name. My topic, for the sake of clarification, dear "[A]," is "thinking on behalf of Germany as a competitive location." I can assure you that there are now a lot of politicians who do not consider my remarks on this to be "charlatanry" at all. Perhaps you could join the more than 220,000 people who have downloaded our latest basic report "Energiepolitik im Konzeptnebel" published in late January ([Link]). Mr. [Blogger] correctly pointed out that I am not a physicist. But complex questions are necessarily always interdisciplinary. In my company we work with networks of consultants which include physicists as well as theoretical and synoptic meteorologists, physical chemists, biologists and other experts on the issues at stake here. Other people invited to the committee were agricultural scientists, political scientists, government bureaucrats and a churchman. But because, in [Blogger's] and your opinion, they represented the True Teaching, THEY were of course allowed to be heard by the Landtag [ = regional parliament] without objection.

3) Commentator nickname B (24 June 2014 10:25): Where did $[A]$ call for censorship? He rather called for reasonable classification: a disproved and untenable marginal opinion on physics by a non-specialist should rightly not be presented as an "expert opinion" in an expert hearing. Of course you may express your opinion freely-but if you spread rubbish, you must also respect the right of all others to call this rubbish rubbish....

4) Commentator real name C (24 June 2014 3:17): @[criticized expert]: So as not to lay myself open to the cheap accusation of being an anonymous sniper, I made an exception and used my name. But the validity of arguments depends just as little on whether someone reveals his real name as it depends on his professional-scientific qualifications.

5) Expert criticized in the blog (28 June 2014 18:11): Dear @[nickname B], you too may express your opinion freely. But if you had expert ARGUMENTS in addition to your opinion-then it might also be interesting. And a name.

6) Commentator nickname D (29.06.2014, 18:11): Mr [criticized expert], there are enough arguments here 
and elsewhere. To remind you:...It remains completely unclear to me what drives you to adhere to a hypothesis that has crumbled into dust both experimentally and theoretically. As an economist without a scientific education, you don't seem to have any knowledge of Karl Popper and the falsification of hypotheses. Your "cooling" is done. Period.

This short dialogue between four people, including the criticized expert, already reveals a great deal: The role of the expert, assigned to the latter externally by his invitation to the regional parliament's committee, is questioned by readers and commentators alike, but defended by the expert himself.

The commentators who call into question the expert status of the individual criticized explicitly and in detail by the blog do so against the background of the various expectations they obviously have of experts and which they do not consider fulfilled here: (1) the expectation of education relevant to the field ("charlatan," "by a non-specialist," "economist without a scientific education"); and (2) the expectation of a scientific mindset and corresponding argumentation ("completely obvious pied piper arguments," "disproved untenable marginal opinion on physics," "spreading rubbish," "adhere to a hypothesis that has crumbled to dust both experimentally and theoretically," "don't seem to have any knowledge of..."). The fact that this discourse participant is perceived by politicians as an expert and, given his invitation to advise the regional parliament, is taken seriously by them, clearly disappoints the other participants' expectations to such an extent that it leads to emotionally laden language, including strongly evaluative expressions ("pied piper arguments," "crumbled to dust," "rubbish," "adhere") and speech acts signalling impatience and frustration ("If this is what realpolitik looks like, then good night"). In this excerpt the expert defends himself against these accusations not with factual arguments but with (repeated) criticism of the communicative behaviour of his opponents ("calling for censorship," "doesn't mention his name") and of the discourse itself ("But because, in [Blogger's] and your opinion, they represented the True Teaching, THEY were of course allowed to be heard...without objection"). He thus formulates expectations that are rather unusual for communication on social media, but are quite common in science communication (e.g., use of clear names instead of nicknames). These expectations are understandable in view of the fact that, as a person already named in the blog's title, he finds himself in an asymmetrical situation vis-àvis the other commentators with regard to the possibility of anonymity and data protection. At the same time, they are surprising because he argues politically rather than scientifically. Since he is not able to justify his right to speak (disputed by all participants in the communication) by referring to his education and thus cannot fulfil expectation (1) ("that I am not a physicist"), he seeks to ground his expertise in an interdisciplinary background ("in my company we work with networks of consultants") and to back it up using a relatively weak form of majority argumentation ("there are now a lot of politicians who...," "Perhaps you could join the more than 220,000 people who...").

Interestingly, both camps agree that the issue to be negotiated must be primarily about the validity of factual arguments and not mere opinions. Both camps also point out that these arguments can be supported by consensus, i.e., by the consent of others. However, the positions differ in the extent to which a relevant specialist education-in this case in the natural sciences and physics - is a prerequisite for the quality of the argumentation. Possibly, these expectations differ so sharply because the commentators have a stronger perception of the discourse as scientific, despite the media environment, while the expert, as already mentioned, argues strongly from a political perspective.

\subsection{Ways to Rationality via Promoting and Offering Empathy}

There now follow two sequences in which expectations are also disappointed, but in which the resulting emotionality is countered in a de-escalating and objectifying fashion through expectations of or readiness to display empathy. Interestingly, it is the commentators rather than the two experts (the science blogger and the criticized expert) who in an objective tone demand empathy, serious responses, understandable explanations, and well-founded justifications. This in turn suggests some very specific expectations of scientists who communicate with the public: namely that they are patient and reasonable, that they remain objective and communicate comprehensibly. Thus, these expectations match the expectations of the scientists and their willingness to empathize as outlined in Section 4 (4.1 and 4.2): appropriate handling of the complexity of the topic, insights into cognitive processes, and transparency with regard to the validity of the statements made.

Italics (role assignment), underlining (action evaluation) and upper case (FORMULATION OF EXPECTATIONS REGARDING EMPATHY) have been used to emphasize how the statements are argued.

\section{Example Sequence 2:}

1) Commentator nickname E (24 June 2014 13:03): An amateur like me sees the greenhouse discussion as follows:...as I said, that's how I see it as a non-expert.

2) Blogger (Scientist) (24 June 2014 17:49): that you as a non-expert know what the experts are doing wrong....

3) Commentator nickname E (25 June 2014 14:21): Dear Mr. [Blogger], this kind of reaction will bring you exactly THE OPPOSITION THAT YOU...COMPLAIN 
ABOUT. It's really not necessary. IN ORDER TO ACHIEVE THE ACCEPTANCE THAT YOU WOULD LIKE, I THINK IT WOULD MAKE SENSE FOR YOU TO BROADEN YOUR HORIZONS AND PAY MORE ATTENTION TO THE GENERAL PUBLIC. FOR EXAMPLE, IT WOULD BE HELPFUL-AND WOULD CLEAR UP MISUNDERSTANDINGS-if you could tell me whether and, if so, why I am mistaken....I WOULD ASK YOU TO EXPLAIN to me (and possibly to one or two interested readers) WHY YOU (OBVIOUSLY) THINK THAT IS WRONG. PERHAPS YOU COULD ALSO CITE VARIOUS SOURCES....Thank you very much.

4) Blogger (Scientist) (26 June 2014 16:31): Dear Mr. [E], I don't always have time TO REPLY TO ALL THE THESES THAT APPEAR HERE. Very briefly:...Incidentally, I have nothing against discussing such questions with laymen (that is the purpose of this blog), but I'm surprised when laymen claim full of conviction that all experts have been committing a "terrible blunder" in their basic understanding of the greenhouse effect for more than a century. BEAR IN MIND that every semester thousands of physics students gain an understanding of these things from scratch, including undoubtedly many highly intelligent and critical minds. HOW LIKELY IS IT that such a terrible blunder exists that no one has ever noticed?

The request of the self-confessed layman ("an amateur like me," "as a non-expert") that the scientist demonstrate more empathy towards the public ("broaden your horizon," "pay more attention to the general public") is connected to expectations as to how this empathy can be fulfilled ("clear up misunderstandings," "explain," "cite various sources"). These correspond essentially to the expectations towards experts elaborated in example sequence 1 (see Section 5.1). The scientist complies with these expectations, but only from a perspective of egocentric (and not allocentric) empathy ("I don't always have time," "very briefly," "I'm surprised") while demanding empathy in return in the form of prompts and prompting questions ("Remember", "How likely is it...?"). The layman's attempt to achieve more objectivity with his demand for empathy in response to the scientist's ironic reaction (2) ("It's really not necessary") is ultimately successful, because the requested explanation follows-and possibly also because the layman shows that he too is capable of allocentric empathy on the basis of expectations of expectations ("In order to achieve the acceptance you would like").

Example Sequence 3:

1) Commentator nickname G (24 June 2014 00:08): Dear $\mathrm{Mr}$ [criticized expert], it is actually part and parcel of general education that the air temperatures reach their daily maximum some hours after the sun has reached its zenith (given stable weather conditions).
2) Expert criticized in the blog (28 June 2014 18:03): Mr. [G], before you boast of your general education, YOU SHOULD PAUSE FOR A MOMENT AND ASK YOURSELF IF YOU HAVE CORRECTLY UNDERSTOOD THE PROBLEM AND IF YOU HAVE THE SAME VIEW OF THE PROBLEM AS THE PARTICIPANT YOU HAVE CRITICIZED. Otherwise we get the proverbial comparison of apples and pears.

3) Commentator nickname G (29 June 2014 18:01): Dear $\mathrm{Mr}$ [criticized expert], first and foremost, I THINK IT IS IMPORTANT TO POINT OUT the differences....which unfortunately is often neglected in such discussions...BUT YOU ARE RIGHT, IN A DISCUSSION YOU SHOULD ALREADY SEE WHETHER YOU HAVE UNDERSTOOD YOUR COUNTERPART'S PERCEPTION OF THE PROBLEM AND WHETHER YOU CAN REPRESENT IT CORRECTLY. IF I HAVE SOMEHOW MISREPRESENTED ANY OF YOUR STATEMENTS, JUST SAY SO. I HAVE NO PROBLEM CORRECTING MYSELF.

The example sequence follows a pattern that is repeated several times in the comments section: A commentator approaches the criticized expert directly with a question or statement (certainly not without provocative elements: "it is... part and parcel of general education"), to which the expert replies in a manner ranging from the sharp-tongued to the aggressive. The commentator reacts with pronounced objectivity, expressed in both polite salutation and self-revelation ("I have no problem correcting myself"). In response to the expert's appeal for empathy, which is purely rhetorical, since it is phrased aggressively ("before you boast of your general education, you should...ask yourself"), the commentator accepts and confirms the necessity for empathy and thus shifts the discussion by his contribution from the emotional back to the objective level ("But you are right, in a discussion you should already see whether you have understood your counterpart's perception of the problem....If I have somehow misrepresented any of your statements, just say so").

\section{Synthesis and Conclusion}

The following conclusions are based on an exploratory approach, as already mentioned, both with regard to the expectations held by the scientists and to the analysis of the blog comments. They represent an attempt to demonstrate the relevance of empathy in science communication (especially regarding the conflict-laden negotiation of social identities) and to stimulate empirical research on it.

Scientists who are willing to communicate their findings to the public actively engage with the public's expectations. They thus demonstrate both experience- and judgement-based empathy with groups. In part, these are expectations of expectations to which they are prepared to respond with allocentric empathy. However, 
they also adjust their communicative attitude, on the basis of egocentric empathy, in order to correct individual and, in their view, inappropriate public expectations of science.

In the science blog we observe that, in the context of science communication, readers actually expect not only that the experts are qualified and competent, but also that they are prepared to report objectively on science, to substantiate findings, to explain complex issues in greater detail, and to deal openly with uncertainties. When the experts become impatient or respond with irony, and when they do not (want to) live up to these expectations due to a lack of empathy or due to, at best, egocentric empathy, the interaction quickly becomes emotionally charged. This, in turn, can be mitigated by the explicit articulation of an expectation of or a willingness to display empathy as a means of returning to the substantive issue as quickly as possible. However, this pattern of action may well be a feature specific to science blogs, forums, etc. and will hardly apply to all blogs and forums on social media, since those who read and leave comments on science blogs can already be expected to have a specific interest and prior knowledge and be willing to communicate constructively (e.g., Schäfer, 2017; Sprain \& Reinig, 2017).

Despite their provisional nature, the evaluation of the interviews and analysis of the comments demonstrate that emotionality is almost inevitable when people with different, hierarchically perceived roles meet, and the scientific content of their communication is complex, socially relevant, and possibly also characterized by uncertainties on both the cognitive and decisionmaking levels (e.g., Kuteeva, 2016). This is also because in such communicative contexts the most diverse expectations collide, heavily influencing direct communicative action in the form of reciprocal expectations of expectations. Empathy appears to be a possible way to resolve or even avoid the resulting communicative conflicts (instead of engaging in more emotional communication, e.g., Schneider, 2019). It would therefore be worthwhile taking a closer look at empathy in science communication not only by means of linguistic methods but also using interdisciplinary approaches in communication science, other social sciences, and the humanities (Bender \& Janich, 2020).

\section{Acknowledgments}

I acknowledge support by the German Research Foundation and the Open Access Publishing Fund of Technische Universität Darmstadt for publishing Open Access. Further, my thanks go to the Klaus Tschira Foundation for research funding, to Maike Sänger for collecting data (interviews), and to Kathleen Cross for proofreading.

\section{Conflict of Interests}

The author declares no conflict of interests.

\section{References}

Beckers, K. (2012). Kommunikation und Kommunizierbarkeit von Wissen: Prinzipien und Strategien kooperativer Wissenskonstruktion [Communication and communicability of knowledge: Principles and strategies of cooperative knowledge construction]. Berlin: Schmidt.

Bender, M., \& Janich, N. (2020). Empathie in der Wissenschaftskommunikation: Eine Forschungsskizze [Empathy in science communication: A research sketch]. In K. Jakob, P. Konerding, \& W.-A. Liebert (Eds.), Sprache und Empathie: Linguistische und interdisziplinäre Zugänge [Language and empathy: Linguistic and interdisciplinary approaches] (pp. 425-449). Berlin and New York, NY: De Gruyter.

Breithaupt, F. (2009). Kulturen der Empathie [Cultures of empathy]. Frankfurt am Main: Suhrkamp.

Breyer, T. (2013). Empathie und ihre Grenzen: Diskursive Vielfalt-Phänomenale Einheit? [Empathy and its limitations: Discursive diversity-Phenomenal entity?]. In T. Breyer (Ed.), Philosophische, psychologische und anthropologische Perspektiven [Philosophical, psychological and anthropological perspectives] (pp. 13-44). Munich: Fink.

Brossard, D., \& Scheufele, D. A. (2013). Science, new media, and the public. Science, 339(6115), 40-41.

Dudo, A. (2013). Toward a model of scientists' public communication activity: The case of biomedical researchers. Science Communication, 35(4), 476-501.

Eriksson, G., \& Thornborrow, J. (2016). Introduction. Special issue: Mediated forms of ordinary expertise. Discourse, Context, and Media, 13(9), 1-3.

Hermanns, F. (2007a). Diskurshermeneutik [Hermeneutics of discourse]. In I. H. Warnke (Ed.), Diskurslinguistik nach Foucault: Theorie und Gegenstände [Discourse linguistics according to/after Foucault: Theory and objects] (pp. 187-210). Berlin and New York, NY: De Gruyter.

Hermanns, F. (2007b). Empathie [Empathy]. In F. Hermanns \& W. Holly (Eds.), Linguistische Hermeneutik [Linguistic hermeneutics] (pp. 127-174). Tübingen: Niemeyer.

Herrmann-Giovanelli, I. (2013). Wissenschaftskommunikation aus der Sicht von Forschenden: Eine qualitative Befragung in den Natur- und Sozialwissenschaften. [Science communication from the perspective of researchers: A qualitative survey within the natural and social sciences]. Konstanz: UVK.

Hoffman, M. L. (2000). Empathy and moral development: Implications for caring and justice. Cambridge: Cambridge University Press.

Hyland, K. (2009). Constraint vs. creativity: Identity and disciplinarity in academic writing. In M. Gotti (Ed.), Commonality and individuality in academic discourse (pp. 25-52). Bern: Lang.

Jäger, L. (1996). Expertenkultur und Sprachkultur: "Innersprachliche Mehrsprachigkeit" und das Problem 
der Transparenz des Expertenwissens [Expert culture and language culture: "Intralingual multilingualism" and the problem of transparency of expert knowledge]. In K. Böke, M. Jung, \& M. Wengeler (Eds.), Öffentlicher Sprachgebrauch: Praktische, theoretische und historische Perspektiven [Public use of language: Practical, theoretical and historical perspectives] (pp. 68-76). Opladen: Westdeutscher Verlag.

Klenk, M. (2013). The form of expectation: Considerations on social structure. Cybernetics and Human Knowing, 20(3/4), 173-187.

Kuteeva, M. (2016). Research blogs, wikis, and tweets. In K. Hyland \& P. Shaw (Eds.), The Routledge handbook of English for academic purposes (pp. 431-443). London: Routledge.

Luhmann, N. (1976). Sinn als Grundbegriff der Soziologie [Meaning as a basic concept of sociology]. In J. Habermas \& N. Luhmann (Eds.), Theorie der Gesellschaft oder Sozialtechnologie: Was leistet die Systemforschung? [Theory of society or social technology: What does systems research achieve?] (pp. 25-100). Frankfurt am Main: Suhrkamp.

Maillé, M-Ė., Saint-Charles, J., \& Lucotte, M. (2010). The gap between scientists and journalists: The case of mercury science in Québec's press. Public Understanding of Science, 19(1), 70-79.

Motta-Roth, D., \& Scotti Scherer, A. (2016). Science popularization: Interdiscursivity among science, pedagogy, and journalism. Bakhtiniana: Revista de Es- tudos do Discurso, 11(2), 171-194. https://doi.org/ 10.1590/2176-457323671

Rahmstorf, S. (2014, June 20). Der Anti-Treibhauseffekt des Herrn Ermecke [The Anti-greenhouse effect of Mr. Ermecke]. Spektrum.de. Retrieved from https://scilogs.spektrum.de/klimalounge/der-antitreibhauseffekt-herrn-ermecke

Schäfer, M. S. (2017). Wissenschaftskommunikation online [Science communication online]. In H. Bonfadelli, B. Fähnrich, C. Lüthje, J. Milde, M. Rhomberg, \& M. S. Schäfer (Eds.), Forschungsfeld Wissenschaftskommunikation [Research area science communication] (pp. 275-293). Wiesbaden: Springer VS.

Schneider, S. (2019). The takeover of science communication: How science lost its leading role in the public discourse on carbon capture and storage research in daily newspapers in Germany. Geoscience Communication, 2(1), 69-82. https://doi.org/10.5194/gc-269-2019

Sprain, L., \& Reinig, L. (2017). Citizens speaking as experts: Expertise discourse in deliberative forums. Environmental Communication, 12(3), 357-369. https://doi.org/10.1080/17524032.2017.1394894

Weingart, P. (2003). Wissenschaftssoziologie [The sociology of science]. Bielefeld: Transcript.

Weingart, P., \& Guenther, L. (2016). Science communication and the issue of trust. Journal of Science Communication, 15(5), C01. https://doi.org/10.22323/2. 15050301

\section{About the Author}

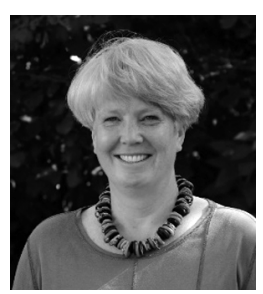

Nina Janich $(P h D)$ is Professor for German Linguistics at Technische Universität Darmstadt since 2004. Her research focuses on scientific language/scientific communication (e.g., communication of scientific uncertainty, discourses of climate change, and biodiversity), text and discourse linguistics, language criticism/linguistic culture research, and advertising linguistics/business communication. She is full member of acatech-National Academy of Science and Engineering, of the Scientific Society of Goethe University Frankfurt-and of the DGPuK (Deutsche Gesellschaft für Publizistik-und Kommunikationswissenschaft/The German Communication Association). 